\title{
Mechanism on Moho offset induced by aseismic slip of deeply buried faults
}

\author{
Zhen Fu • Hai-ming Zhang • Shu-wen Dong
}

Received: 9 December 2013/Accepted: 24 February 2014/Published online: 11 April 2014

(C) The Seismological Society of China, Institute of Geophysics, China Earthquake Administration and Springer-Verlag Berlin Heidelberg 2014

\begin{abstract}
Recent high-resolution deep seismic reflection profile across the Kunlun fault in northeastern Tibet shows clearly that the Moho is cut off by a complex thrust fault system. Moho offset is a general phenomenon, but little is known about the dynamic mechanism. In this study, contact models with Maxwell materials are used to simulate the mechanical process of Moho offset induced by the aseismic slip of deeply buried faults. Based on the seismic reflection data, we project a single fault model and a complex fault system model with two faults intersecting. The deformations of the Moho, the aseismic slips, and contact stresses on faults in different models are discussed in detail. Results show that the Moho offset might be produced by aseismic slip of deeply buried faults, and the magnitude is influenced by the friction coefficient of faults and the viscosity of the lower crust. The maximum slip occurs near the Moho on the single fault or at the crossing point of two intersecting faults system. Stress concentrates mainly on the Moho, the deep end of faults, or the crossing point. This study will throw light on understanding the mechanism of Moho offset and aseismic slip of deeply buried faults. The results of complex fault system with two faults intersecting are also useful to understand the shallow intersecting faults that may cause earthquakes.
\end{abstract}

\footnotetext{
Z. Fu $(\bowtie) \cdot$ S. Dong

Chinese Academy of Geological Sciences, Beijing 100037,

China

e-mail: fuzhen@cags.ac.cn

H. Zhang

School of Earth and Space Sciences, Peking University,

Beijing 100871, China

e-mail: zhanghm@pku.edu.cn
}

Keywords Moho offset · Aseismic slip - Deeply buried faults $\cdot$ Numerical simulation $\cdot$ Viscoelastic contact model

\section{Introduction}

Since the Moho discontinuity is a global, prominent seismic velocity boundary, Moho geometries reveal the interaction of the crust and the upper mantle and are a key factor to understand the tectonic evolution of the lithosphere. Actually, the Moho is discontinuous in the lateral direction. A variety of data reveals that Moho offset is a very common phenomenon in the world (Zhu and Helmberger 1998; Zhang et al. 2009; ten Brink et al. 1990). In some regions such as terrane boundary, the Moho is detected to be cut off by deeply buried faults and overlapping in the vertical section (Hirn et al. 1984; Wittlinger et al. 2004; Vergne et al. 2002; Shi et al. 2009).

For example, deep seismic reflection transect across the foreland of the Dabie mountain shows that the north-dipping Moho is cut off by three large thrust faults. It suggests a northward Mesozoic subduction of the Yangtze plate (Gao et al. 2004). Deep seismic reflection data from the transect of the Southern Urals also document a $\sim 5 \mathrm{~km}$ vertical offset in the Moho beneath the Uralian foreland in the Makarovo fault zone, which is interpreted to be an Archean or Early Proterozoic fault zone (Diaconescu et al. 1998). Receiver functions derived from teleseismic data show a sharp Moho offset by thrust faults beneath the northeast Tibetan plateau (Shi et al. 2009; Vergne et al. 2002). Moho offset can also be inferred by density anomaly (ten Brink et al. 1990; Hurukawa 1983).

Recently, Moho offset has been further confirmed by more and more high-resolution deep seismic reflection data based on the funding of SinoProbe (Wang et al. 2011; 

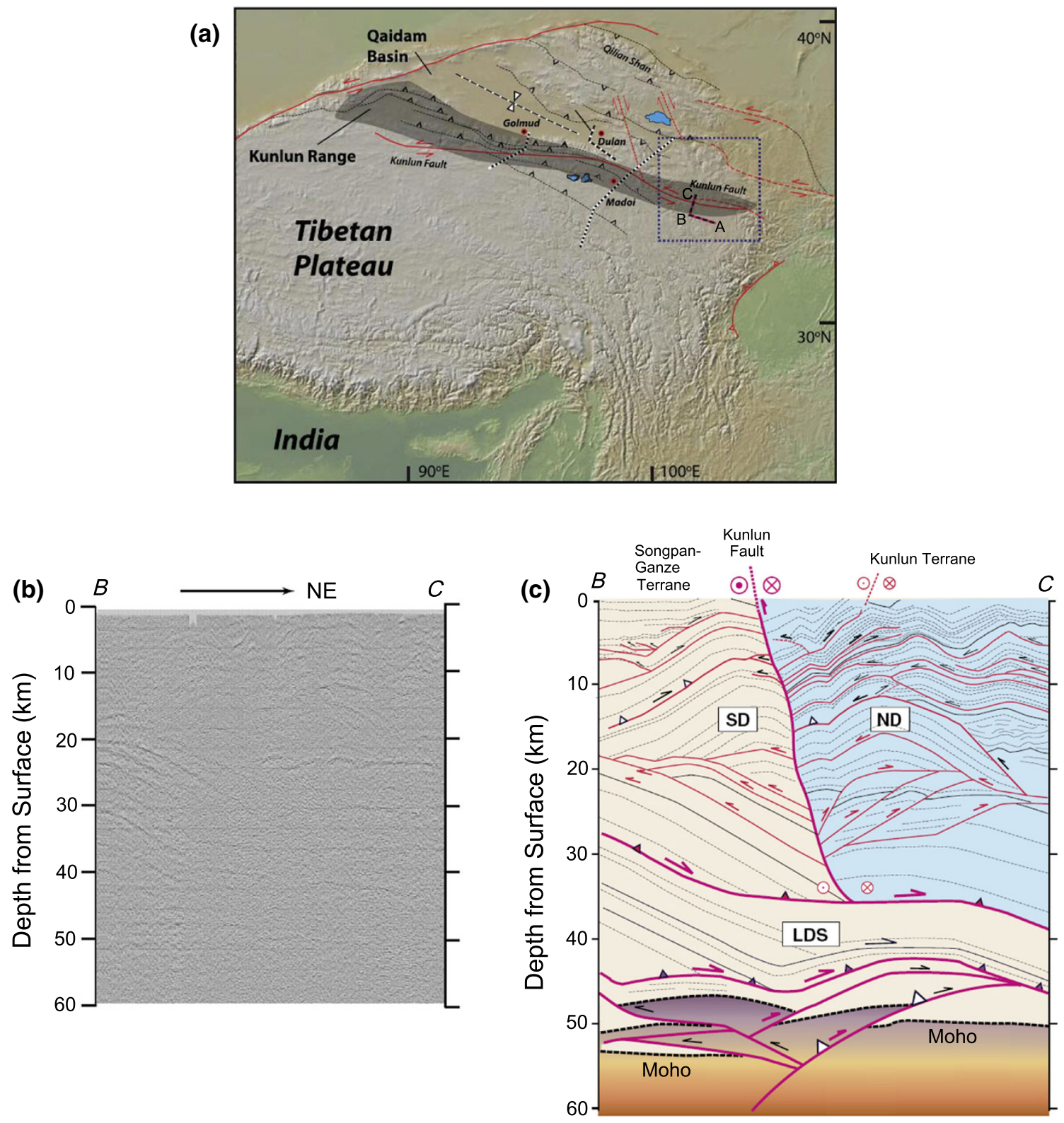

Fig. 1 Seismic reflection profile and interpreted structural section across the Kunlun fault (modified from Wang et al. 2011). a Location of the seismic reflection profile in dashed lines in the pane. The profile is consisted of two lines, AB and BC. Profile AB is parallel to the Kunlun range (marked in dark gray) and is not considered in this study. Profile BC, which is across the Kunlun fault, is perpendicular to profile AB. b Uninterpreted seismic reflection profile BC (refer to Wang et al. (2011) for details). c Interpreted structural section of profile BC. At both sides of the Kunlun fault is a thrust fault system called "flower structure". The Kunlun fault terminates at a sub-horizontal decollement. Note that the Moho beneath the Kunlun fault is cut off by a complicated thrust fault system with the faults intersecting

Dong et al. 2013; Gao et al. 2013; Wang et al. 2012; Hou et al. 2012). Specially, the deep reflection profile across the left-slip Kunlun fault in northeastern Tibet provides an unprecedented detailed lithosphere structure, which is shown in Fig. 1 (Wang et al. 2011). Beneath the Kunlun fault, the Moho is cut off at several places multiple times by a complex thrust fault system and overlapped strongly.

Although the phenomenon of Moho offset is broadly observed by seismic waves, research on the dynamic mechanism is still rare. The deeply buried faults cutting off the Moho contain two types. One is the faults extending to the ground surface from the depth. They have been widely concerned by researchers because of the close relations to earthquakes (McGeary 1989; Huang et al. 2011). A typical example among them is the San Andreas Fault (Henstock and Levander 2000). The other is the deep ductile shear zones, which are located mainly in the lower crust and the upper mantle and completely buried by the overlying stratum. With tectonic compression, they produce aseismic slip along the fault plane instead of earthquakes, which 
(a)

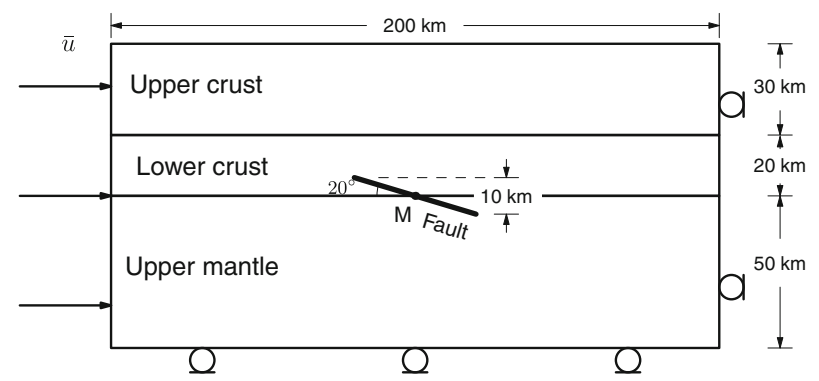

(b)

Model 2

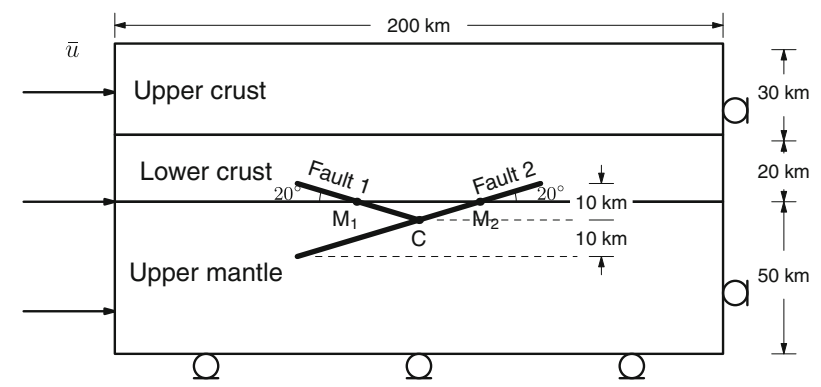

Fig. 2 Sketch map for finite element model, initial geometry, and boundary conditions. a Model 1. A single fault cutting the Moho in depth is included. b Model 2. Two intersecting faults, both cutting the Moho in depth, are included. Thick black lines indicate faults. For the sake of clarity, finite element mesh is not shown. In Model 1, intersection point of the fault and the Moho (interface between the lower crust and the upper mantle) is marked as $M$. While in Model 2, intersection points of the two faults (Fault 1 and Fault 2) with the Moho are marked as $M_{1}$ and $M_{2}$, respectively. The two faults intersect at point $C$. Both models are composed of the upper crust, the lower crust, and the upper mantle. Geometry sizes are marked. Right side and bottom side are fixed in the horizontal and vertical directions, respectively. Displacement $\bar{u}$ is imposed at the left side

usually occur on the brittle fracture in the upper crust. The deeply buried ductile faults, which are independent of earthquakes, are rarely studied by researchers. Thus, the nature of aseismic slip caused by deeply buried faults is not clear, though it is very important in understanding the dynamic process of Moho offset.

In this study, we try to investigate the mechanism of Moho offset by numerical simulation using two conceptional models, which are designed according to the high-resolution deep seismic reflection data across the Kunlun fault. We mainly attempt to discuss the effect of different fault geometry and material parameters on Moho offset and the characteristics of aseismic slip theoretically. The modeling results can also help us to understand the deformation of similar earthquake faults since they are rarely discussed due to the complexity and difficulty.

\section{Model setting}

Considering the long-time deformation of the Moho and aseismic slip of deeply buried faults, we use contact models with Maxwell viscoelastic material in simulation. Contact problem is highly nonlinear and difficult to convergence, but it is very suitable for describing the discontinuity of displacement on both sides of faults especially for Moho offset (Fu 2008; Fu et al. 2013). Due to relative displacements of faults depending on the total stresses in this nonlinear problem, gravity is considered in all simulations. The commercial finite element code ANSYS is employed for this study because it is well suited to analyzing geomechanical problems over a wide range of scales.

The two-dimensional models are set up along the reflection seismic profile $B C$ across the Kunlun fault
Table 1 Material parameters used in finite element models

\begin{tabular}{lclll}
\hline Medium & $\begin{array}{l}\text { Young's } \\
\text { modulus }(\mathrm{MPa})\end{array}$ & $\begin{array}{l}\text { Poisson's } \\
\text { ratio }\end{array}$ & $\begin{array}{l}\text { Density } \\
\left(\mathrm{kg} / \mathrm{m}^{3}\right)\end{array}$ & $\begin{array}{l}\text { Viscosity } \\
(\mathrm{Pa} \mathrm{s})\end{array}$ \\
\hline Upper crust & $8.9 \times 10^{4}$ & 0.25 & 2,700 & $10^{23}$ \\
Lower crust & $1.1 \times 10^{5}$ & 0.28 & 2,900 & $10^{20}$ \\
Upper mantle & $1.45 \times 10^{5}$ & 0.34 & 3,400 & $10^{21}$ \\
\hline
\end{tabular}

(Fig. 1a). The geometries of the models are shown in Fig. 2. Because the main purpose of modeling is focused on Moho offset, the other aspects of the reflection profile are ignored and will not be discussed. Two models are presented with a single fault and a fault system with two crossing faults, respectively, both cutting off the Moho. The faults in the models are simulated with frictional sliding interfaces that employ a simplified Coulomb friction law:

$\tau_{c}=\mu \sigma_{n}$

which implies that slip occurs, if the shear stress exceeds a critical value $\left(\tau_{c}\right)$ defined by the product of the normal stress $\left(\sigma_{n}\right)$ and the friction coefficient $(\mu)$.

The two models in Fig. 2 employ vertical section and plane strain conditions with $200 \mathrm{~km}$ long and $100 \mathrm{~km}$ deep. They are consisted of a viscoelastic three layer lithosphere: the upper crust, the lower crust, and the upper mantle with the thicknesses of 30,20 , and $50 \mathrm{~km}$, respectively. The right sides (north of the Kunlun fault) of the models are fixed in horizontal direction. The bottoms of the models are fixed in vertical direction. The left sides (south of the Kunlun fault) are imposed with horizontal displacement to simulate the tectonic compression. The imposed displacement increases with the maximum value of $20 \mathrm{~km}$.

The material parameter can be obtained from seismic velocity structure (Wang et al. 2013; Karplus et al. 2011; 
(a)

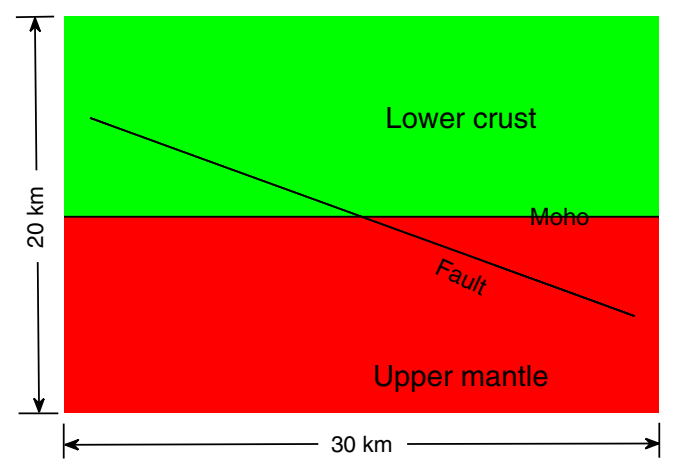

(b)

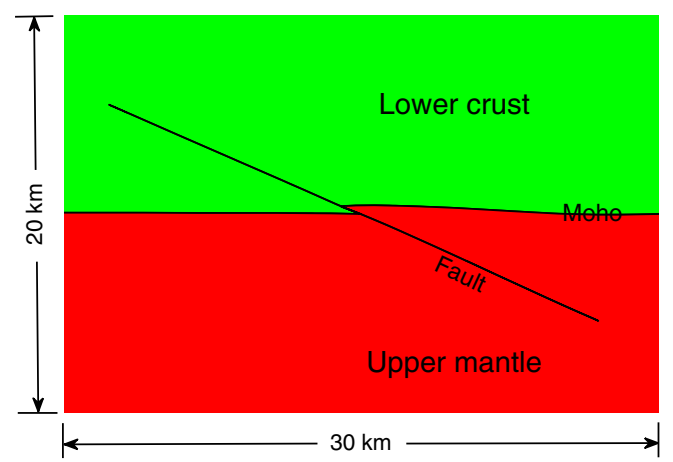

Fig. 3 Deformation of the Moho and the fault before and after loading for Model 1. a Deformation of the Moho and the fault before loading. b Deformation of the Moho and the fault after loading. Black line denotes the fault. Regions in green and red stand for the lower crust and the upper mantle, respectively

Mechie et al. 2012). According to the empirical relationship between wavespeeds and density as equation (2) (Brocher 2005), we can calculate the density of the model region.

$$
\begin{aligned}
\rho= & 1.6612 V_{\mathrm{p}}-0.4721 V_{\mathrm{p}}^{2}+0.0671 V_{\mathrm{p}}^{3}-0.0043 V_{\mathrm{p}}^{4} \\
& +0.000106 V_{\mathrm{p}}^{5}
\end{aligned}
$$

in which $\rho$ is the density with the unit of $\mathrm{g} / \mathrm{cm}^{3}$, and $V_{\mathrm{p}}$ is the velocity of $\mathrm{P}$ waves. The Young's modulus $E$ and the Poisson ratio $v$ can be obtained by equations (3) and (4) as follows:

$V_{\mathrm{p}}=\sqrt{\frac{E(1-v)}{\rho(1+v)(1-2 v)}}$

$V_{\mathrm{s}}=\sqrt{\frac{E}{2 \rho(1+v)}}$

in which $V_{\mathrm{s}}$ is the velocity of $\mathrm{S}$ wave. The model parameters are listed in Table 1.

In Model 1, we investigate the effect of different parameters on modeling result. The friction coefficient denotes the integrated influence of several factors on the slip of fault, such as temperature, fluid, and confining pressure. Values of $0.01,0.05$, and 0.1 are assigned (Smart et al. 2012) to the fault interfaces to estimate the effect of friction on Moho offset quantitatively. The viscosity of the lower crust is also debated (Yamasaki and Houseman 2012; Ryder et al. 2011). We take the viscosity of the lower crust as $10^{19}, 10^{20}$, and $10^{21} \mathrm{~Pa} \mathrm{~s}$, respectively, with the viscosities of the upper crust and the upper mantle fixed as shown in Table 1 (Hilley et al. 2005; England et al. 2013). The Model 2 has two crossing faults with the deep end of Fault 1 terminating at Fault 2 plane (Fig. 2b). It is assigned to find out the effect of fault geometry on the deformation of the Moho. So, parameters in Model 2 are fixed in calculating with the viscosity of $10^{20} \mathrm{~Pa}$ s for the lower crust, and the friction coefficient is set as 0.1 .

The modeling is implemented in two analysis steps. During the first step with duration of $5 \times 10^{11} \mathrm{~s}$ (long enough to relax the stresses in the lower crust and the upper mantle), the loading is imposed with the gravity and linearly increased displacement in the left sides of models. During the second step with the same duration as the first one, boundary condition and load at the end of the first step keep unchanged in order to estimate the behavior on the viscous relaxation of the lower crust and the upper mantle.

\section{Numerical results}

\subsection{Model 1}

The single fault in Model 1 produces a reverse slip in the compression condition that cuts off the Moho (Fig. 3) with friction coefficient of 0.1 and material parameters as shown in Table 1. At the beginning of loading, the Moho is horizontal and consecutive (Fig. 3a). But, at the end of deformation, the Moho is offset and obvious deformation, especially on the hanging wall, can be observed (Fig. 3b). The magnitude of Moho offset can be roughly estimated from the figure. The accurate value can be obtained easily from Fig. 4 in different cases. The distance of Moho offset increases rapidly with time due to the linearly increased displacement on the boundary (Fig. 4a) at the first analysis step. When the loading is completed at the end of the first analysis step (the dashed line in Fig. 4a), the slip of the fault at point $\mathrm{M}$ almost reaches the maximum. During the second analysis step, the loading does not increase and remains unchanged. In this case, the slip of the Moho can be seen from the curve in Fig. 4b, which experiences a very short increasing stage of about $3 \mathrm{~m}$ and then decreases 

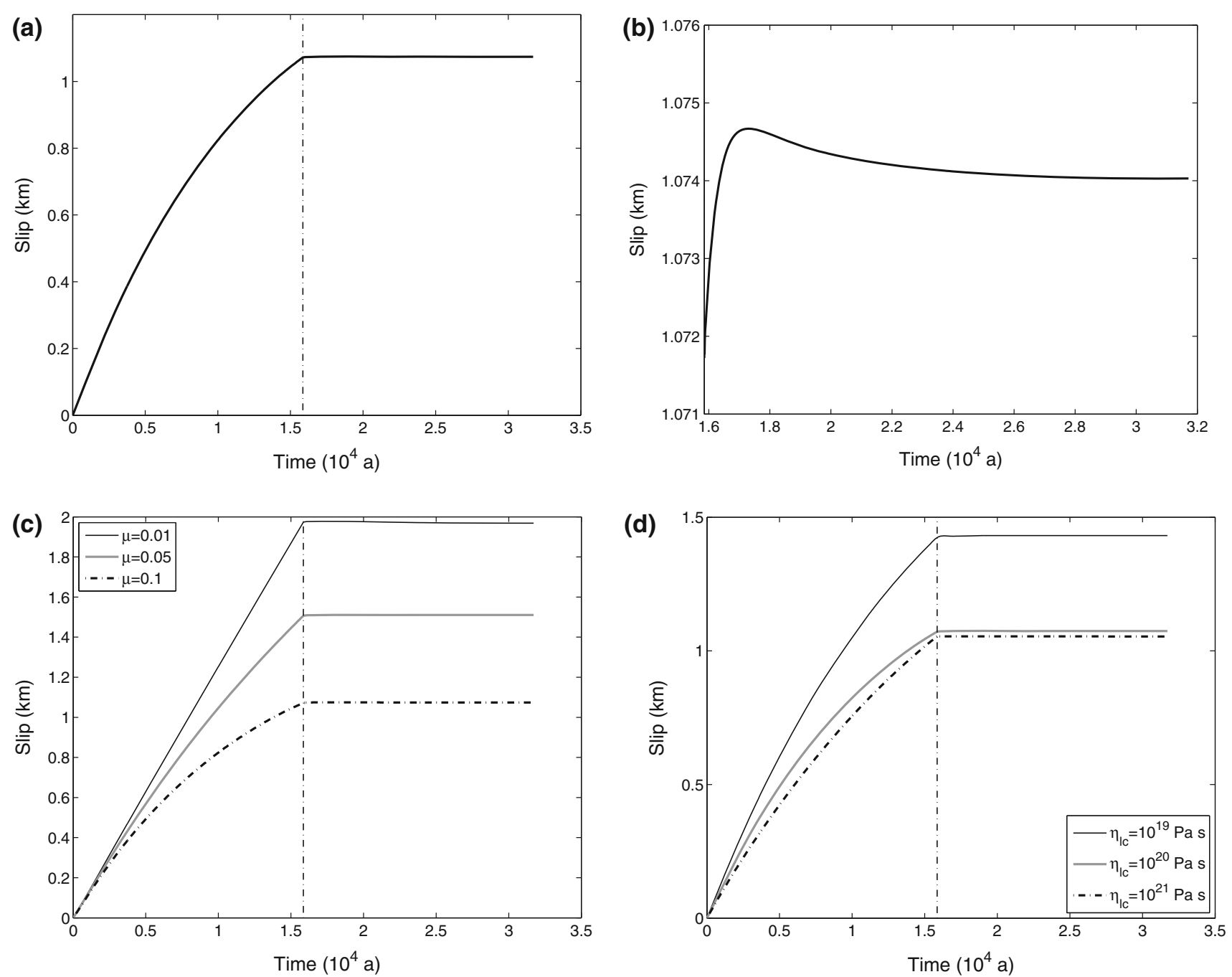

Fig. 4 Slip of the fault on point $M$ in Fig. 2a (i.e., offset of the Moho) with time for Model 1. a Slip curve with time. The displacement load is imposed in two steps. Friction coefficient is 0.1 , and viscosity of the lower crust is $10^{20} \mathrm{~Pa}$ s. Vertical dashed line indicates the instant between two load steps. b Zoomed slip curve for the second load step in a (i.e., the part right to the vertical dashed line). c Comparisons of slip curves with time for friction coefficients of $0.01,0.05$, and 0.1 . Viscosity of the lower crust is the same as that in a. $\mathbf{d}$ Comparisons of slip curves for different viscosities of the lower crust $\left(\eta_{l c}\right)$ with $10^{19}, 10^{20}$, and $10^{21} \mathrm{~Pa} \mathrm{~s}$, respectively. Friction coefficient is 0.1

about $0.5 \mathrm{~m}$, finally keeps unchanged with time. It demonstrates that the viscous relaxation of the lower crust and the upper mantle would not produce obvious change of Moho offset when the load is terminated. Influences of different friction coefficient and viscosity of the lower crust on Moho offset are shown in Fig. 4c, d. Smaller values of friction coefficient cause larger slip of the Moho, which can be easily understood in theoretical analysis. But, simulation results (Fig. 4c) tell us Moho offset increases with decrease of the friction coefficient. Effect of different viscosities of the lower crust on Moho offset is shown in Fig. 4d. Slips of the Moho for the viscosities of $10^{20}$ and $10^{21} \mathrm{~Pa} \mathrm{~s}$ are very close, while slip for the viscosity of $10^{19} \mathrm{~Pa} \mathrm{~s}$ is much larger. This result explicitly illustrates the influence of viscosity of the lower crust on Moho offset.
We can also obtain the evolution of spatial distributions of slip and stress on the whole fault with friction coefficient of 0.1 and viscosity of $10^{20} \mathrm{~Pa} \mathrm{~s}$ for the lower crust (Fig. 5). Figure 5a shows the spatial distribution of the slip of the fault at three different moments: 500, 5,000, and 15,000 years. The two ends of the fault are locked and have no slip. At the early stage of loading, the slip distribution is almost symmetric at the two sides of point $M$. However, with the load imposed continuously, the increasing velocity of the slip at the deep part of the fault (on the right of the dashed line in Fig. 5a) is larger than that at the upper part. The curves become unsymmetric with the maximum slip near the Moho. All curves in Fig. 5a indicate a rapid increasing of fault slip near the Moho (dashed line), which becomes more obvious with the increase of time. It is 

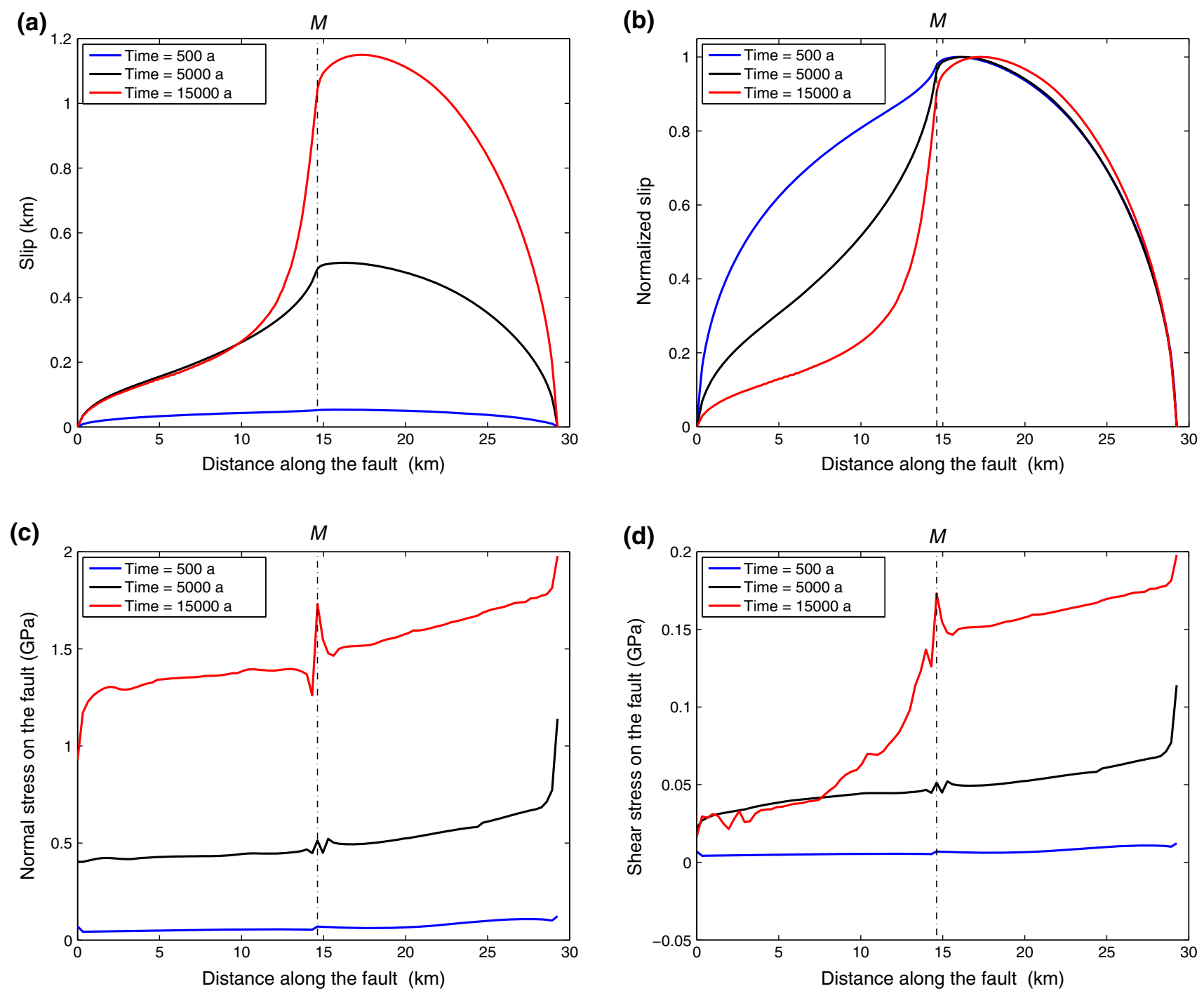

Fig. 5 Spatial distribution of slip, normal, and shear stresses on the fault at different time for Model 1. a Spatial distribution of the slip of the fault at different time. b Same as those in a, except that the slip is normalized. c Spatial distribution of normal stress on the fault at different time. d Spatial distribution of shear stresses on the fault at different time. Vertical dashed line indicates the location of point $M$ (see Fig. 2a). Distance is measured from the upper end of the fault

because that the materials of the lower crust and the upper mantle are quite different. In order to present the change of the pattern of slip curve more clearly, we normalize the results shown in Fig. 5b. Besides the distributions of the slip of the fault, the stress can also be obtained from the simulation. Figure $5 \mathrm{c}$ and d shows the evolution of normal stress (contact pressure) and shear stress (contact friction stress) on the fault, respectively. For the dislocated part of the fault, the shear stress is equal to the product of normal stress and friction coefficient. So, the curves in Fig. 5d have the same shape as in Fig. 5 c. Both stress curves indicate that stress concentration occurs on the two ends of the fault and the Moho (point $M$ ) in the early stage of loading (blue lines in Fig. 5c, d). Then, the stress concentration at the upper end of the fault vanishes gradually. But, it is still distinct at the other two locations, especially at the deep end of the fault (black and red lines in Fig. 5c, d). It may be attributed to that the viscosity of the lower crust is smaller than the upper mantle. The stress relaxes at the upper end faster than at the Moho and the deep end of the fault.

\subsection{Model 2}

Model 2 has two faults that cross each other. It is projected in order to estimate the influence of fault geometry on Moho offset and the characteristics of aseismic slip of deeply buried fault system, particularly for the intersecting 
fault system. In this model, we focus on the resulting difference from one single fault rather than the effect of different material parameters. So, we conduct with the same friction coefficient of 0.1 for both faults. The material parameters in Model 2 are the same as those in Table 1 and fixed throughout this study. Loading is also imposed in the first step and keeps unchanged in the second step.

The slip curves of the Moho on point $M_{1}$ and $M_{2}$ on the two faults (Fig. 2b) present a similar behavior as in Model 1 except the different slopes (Fig. 6). The amount of slip of Fault 1 is much smaller than that of Fault 2, which is because that Fault 1 terminates on Fault 2, causing the downward sliding of the material on the footwall of Fault 1 resisted by Fault 2. On the contrary, the motion of the material on the footwall of Fault 2 is free, subsequently leading to larger slip on Fault 2 than on Fault 1. The slips on both faults are also unchanged similarly to model 1 in the second step of viscous relaxation.

The evolution of spatial distribution of slip on two faults is shown in Fig. 7. The slip curves of Fault 1 are similar to that in Model 1. However, the slip of Fault 2 has different distributions (Fig. 7b, d) since it has two special points, $C$ and $M_{2}$. The maximum is at point $C$. Near point $C$, the slip has a sudden drop and reaches a relative high value at point $M_{2 . .}$ Then the slip is diminished to zero from the middle to the two ends of Fault 2.

The evolution of normal and shear stresses on two faults is shown in Fig. 8. The stress on Fault 1 has the same feature as in Model 1 (Fig. 5c, d). The stress concentrates mainly in the location of the Moho (point $M_{1}$ ) and the deep end of Fault 1 (cross point $C$ ) with time increasing (two dashed lines in Fig. 8a, b). It is not obvious at the upper end of Fault 1 due to the faster stress relaxation of the viscous lower crust. Stress concentration at point $M_{1}$ is attributed to the change of material property on the Moho. While stress concentration at point $C$ can be explained by the fact that the slip of Fault 1 is prohibited by Fault 2 at point $C$. Therefore, the stress concentration at point $C$ is much larger than that at point $M_{1}$. The curves are different for Fault 2 (Figures 8c, d). Stress concentration is significant at the deep end of Fault 2 and point $C$. But, it is not obvious at the upper end of Fault 2 due to the viscous relaxation of the lower crust. At the right side of point $C$, the stress decreases quickly even to zero, which is because that the two contact interfaces of Fault 2 are separated from each other in the process of deformation. The separating is limited in a small area. Results shown in Fig. 8 denote the characteristics of the stress distribution of complex fault system with crossing faults.

The pattern of deformation of the Moho is shown in Fig. 9. Figure 9a shows the initial state of the Moho, in which no deformation occurs. And Fig. 9b shows the final state of the deformation of the Moho with the imposed

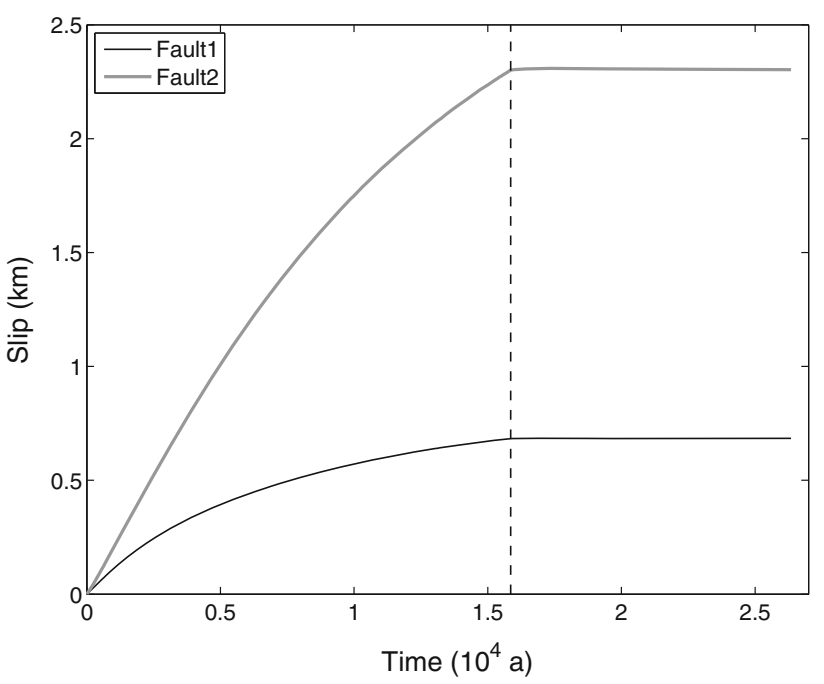

Fig. 6 Slip of Fault 1 at point $M_{1}$ (refer to Fig. 2b) and slip of Fault 2 at point $M_{2}$ (refer to Fig. 2b) with time for Model 2, which are marked in black and red lines, respectively. Vertical dashed line indicates the instant between two load steps. In the first step, the load is imposed by increasing displacement on the boundary. And in the second step, the imposed displacement is fixed to estimate the effect of viscous relaxation on the slip of faults

displacement, in which obvious offset of the Moho can be found. The material between the two intersecting faults is lifted due to the upward motion of the hanging wall of two faults, especially on Fault 2 (Fig. 9b).

\section{Discussion and conclusions}

Our two-dimensional finite element models for viscoelastic contact problems successfully reproduce the dynamic processes of Moho offset and the aseismic slip of deeply buried faults. The results show that once a deep fault or fault system cutting off the Moho, the aseismic slip of faults can cause to Moho offset in tectonic compression. When the loading stops, Moho offset almost does not change with the viscous relaxation of material. The offset of the Moho increases with the decreasing of the friction coefficient of faults and the viscosity of the lower crust. For a single fault, the maximum slip occurs near the Moho, which is located on the middle point of the fault. The slip in the deep portion of the fault increases faster than that in the shallow one with loading, inducing the distribution of the slip on the fault is unsymmetric. Stress concentration occurs at the Moho and the deep end of the fault with time because the upper end of the fault has smaller stress and shorter relaxation time. For the fault system with two crossing faults, the slip of the fault which terminates on the other fault is smaller than that of the latter, because the motion resisted by the other fault. The maximum slip of Fault 1 is on the Moho, and the 

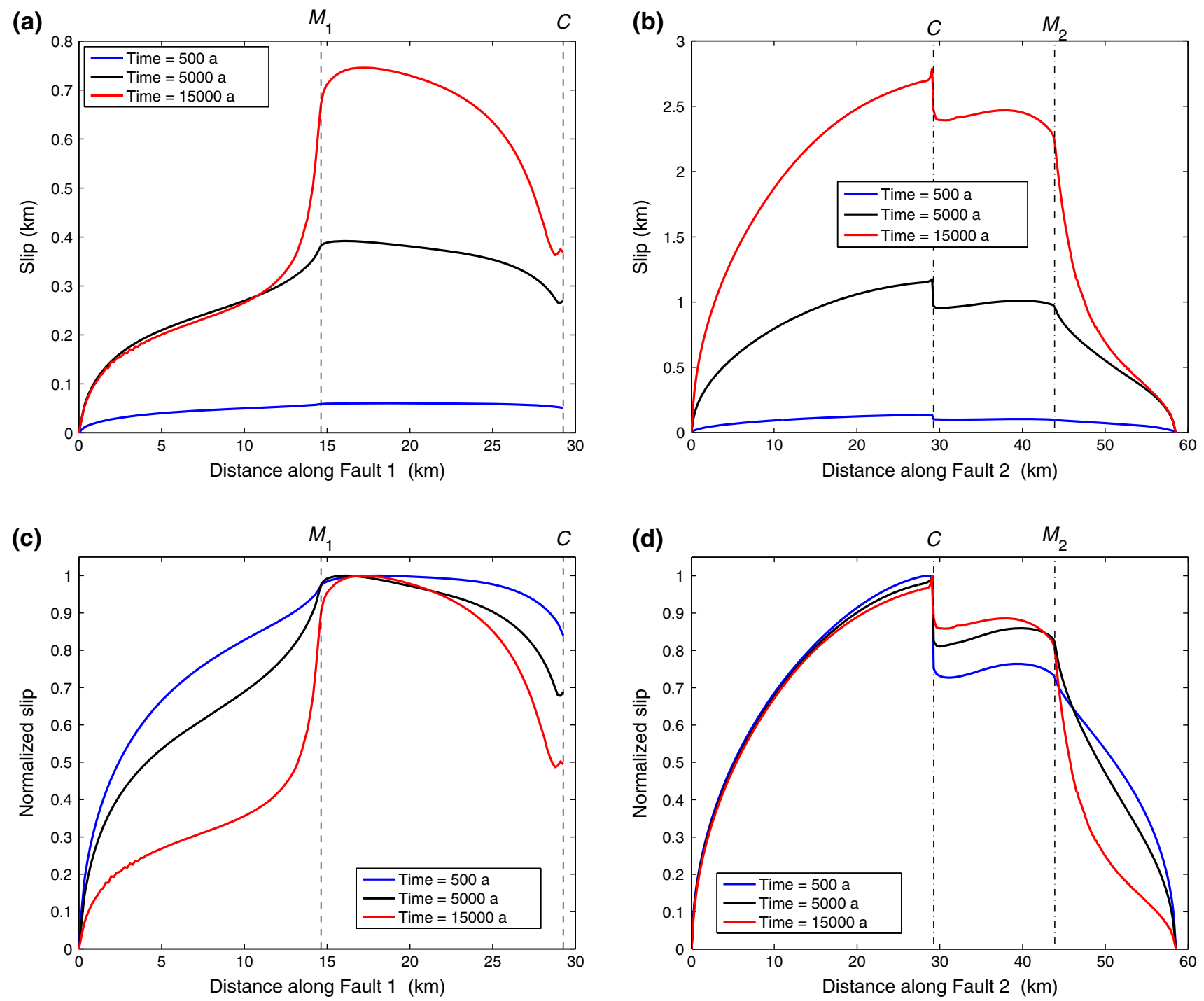

Fig. 7 Spatial distribution of slip on Fault 1 and Fault 2 at different time for Model 2. a Spatial distribution of slip on the Fault 1 at different time. b Spatial distribution of slip on the Fault 2 at different time. c Same as those in a, except that the slip is normalized. d Same as those in $\mathbf{b}$, except that the slip is normalized. Vertical dashed line indicates the locations of points $M_{1}, M_{2}$, and $C$ (see Fig. 2a). Distance is measured from the upper end of Fault 1 and lower end of Fault 2

maximum slip of Fault 2 is at the crossing point of two intersecting faults. The contact stress also concentrates on the Moho and the deep end of faults, similar to that of one single fault. Besides, for Fault 2, stress concentration at the cross point is much more significant than that on the Moho.

The modeling shows that the magnitude of Moho offset is about $1-2 \mathrm{~km}$, which is smaller than that shown in Fig. 1 for about 3-8 km. It may indicate that the profile in Fig. 1 has undergone several tectonic compression since the stop of loading and viscous relaxation would not lower the Moho offset (Figs. 4, 6). It is also possible that the friction coefficient is smaller than the value of 0.1 in this paper.
Whatever, the prominent overlapping of the Moho demonstrates that the region has undergone a strong tectonic compression by the ambient plates.

Furthermore, due to the technical difficulties, study on the complicated fault system is rare. Therefore, research on the dynamics of the two crossing faults in this paper is valuable to understand the nature of the crossing faults in the upper crust causing earthquakes. Although the models proposed in this paper are very simple and preliminary, the results may throw light on understanding the dynamic mechanism of Moho offset induced by aseismic slip of deeply buried faults. Further works of theoretical simulation combined with observation data are needed in near future. 

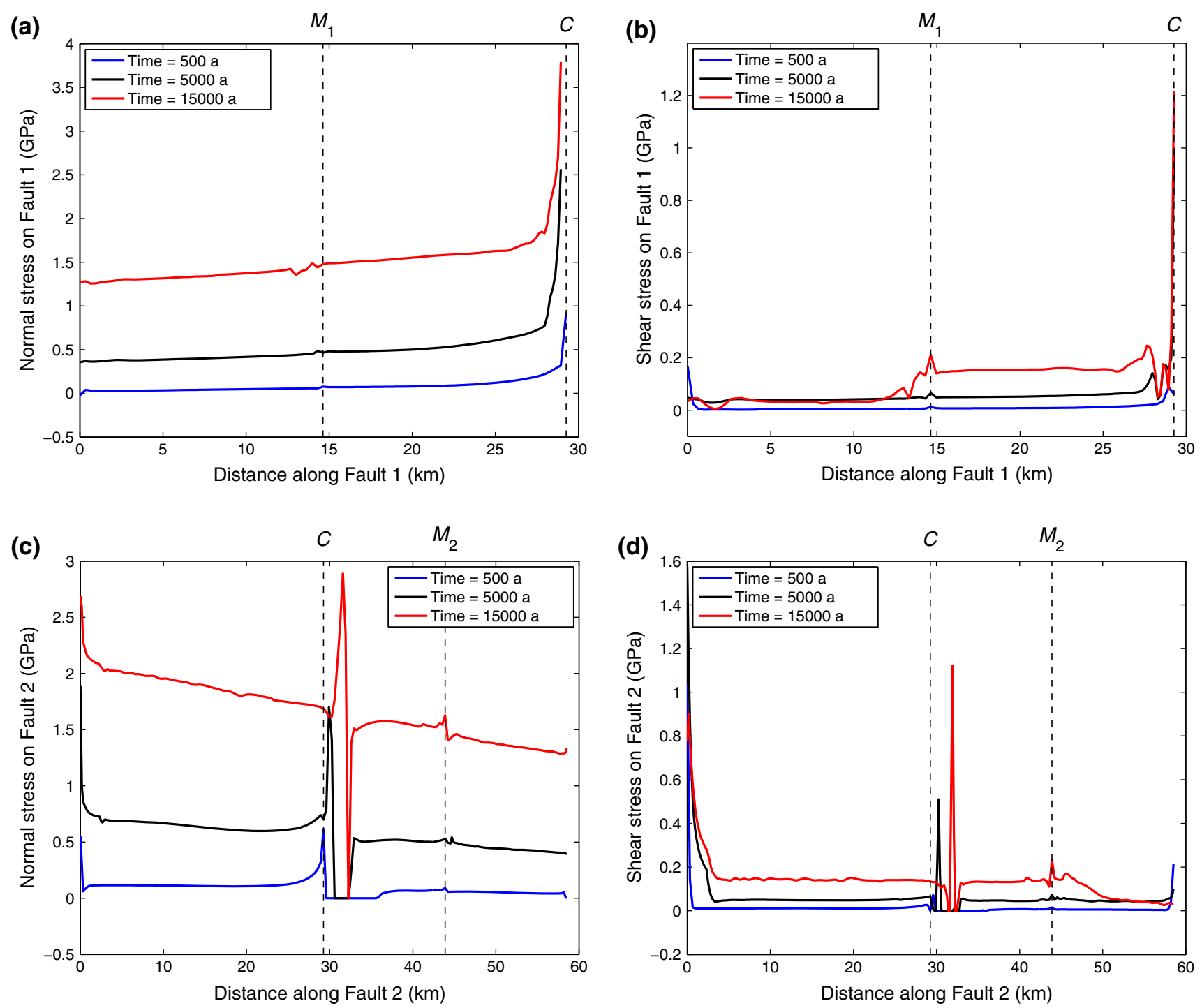

Fig. 8 Spatial distribution of normal and shear stresses on Fault 1 and Fault 2 at different time for Model 2. a Spatial distribution of normal stresses on the Fault 1 at different time. b Spatial distribution of shear stresses on the Fault 1 at different time. c Spatial distribution of normal stresses on the Fault 2 at different time. d Spatial distribution of shear stresses on the Fault 2 at different time. Vertical dashed line indicates the locations of points $M_{1}, M_{2}$ and C (see Fig. 2a). Distance is measured from the upper end of Fault 1 and lower end of Fault 2

(a)

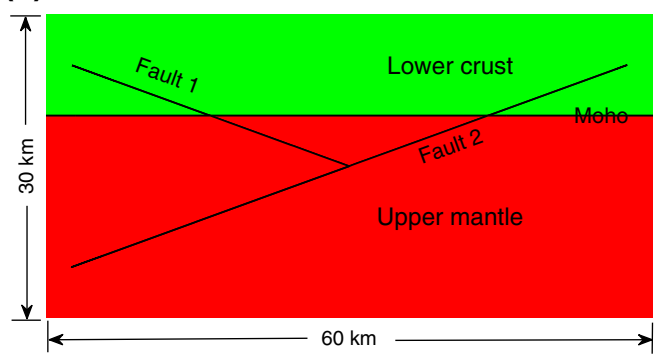

(b)

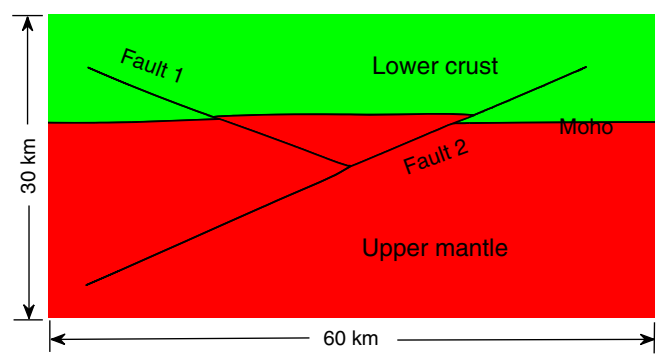

Fig. 9 Deformation of the Moho and the faults system before and after loading for Model 2. a Deformation of the Moho and the faults system before loading. b Deformation of the Moho and the faults system after loading. Black lines denote the faults. Regions in green and red stand for the lower crust and the upper mantle, respectively 
Acknowledgments We gratefully acknowledge Prof. Yong'en Cai for constructive discussions and helpful advices in improving this manuscript. The software ANSYS used in this study is provided by the Department of Geophysics, Peking University. This work was supported by SinoProbe (Grant 08-01), the National Natural Science Foundation of China (Grant Nos. 41174035 and 41130316), the National High Technology Research and Development Program of China (863 Program) (Grant No. 2009AA093401-05), and the Major State Basic Research Development Program of China (973 Program) (Grant No. 2012CB417301).

\section{References}

Brocher TM (2005) Empirical relations between elastic wavespeeds and density in the Earth's crust. Bull Seismol Soc Am 95(6):2081-2092

Diaconescu CC, Knapp JH, Brown LD, Steer DN, Stiller M (1998) Precambrian Moho offset and tectonic stability of the East European platform from the URSEIS deep seismic profile. Geology 26(3):211-214

Dong SW, Gao R, Yin A, Guo TL, Zhang YQ, Hu JM, Li JH, Shi W, Li QS (2013) What drove continued continent-continent convergence after ocean closure? Insights from high-resolution seismic-reflection profiling across the Daba Shan in central China. Geology 41(6):671-674

England PC, Walker RT, Fu BH, Floyd MA (2013) A bound on the viscosity of the Tibetan crust from the horizontality of palaeolake shorelines. Earth Planet Sci Lett 375:44-56

Fu Z (2008) Viscoelastic LDDA method for contact problems and its applications to studies on mechanism of postseismic deformation. PhD Thesis, School of Earth and Space Sciences, Peking University, Beijing (in Chinese)

Fu Z, Zhang H, Cai Y (2013) Mechanism of postseismic deformation of ground surface following the 1999 Chi-Chi earthquake, Taiwan. Chin J Geophys 56(8):2681-2689 (in Chinese with English abstract)

Gao R, Dong S, He R, Liu X, Li Q, Guan Y, Bai J, Li P, Huang D, Qian G, Kuang Z, Li S (2004) Subduction process of the Yangtze continental block from Moho reflection image, South China. J Earth Sci Front 11(3):43-49 (in Chinese with English abstract)

Gao R, Hou HS, Cai XY, Hou HS, Cai XY, Knapp JH, He RZ, Liu JK, Xiong XS, Guan Y, Li WH, Zeng LS, Roecker SW (2013) Fine crustal structure beneath the junction of the southwest Tian Shan and Tarim Basin, NW China. Lithosphere 5(4):382-392. doi:10.1130/L248.1

Henstock TJ, Levander A (2000) Lithosphere evolution in the wake of the Mendocino triple junction: structure of the San Andreas Fault system at 2 Ma. Geophys J Int 140:233-247

Hilley GE, Burgmann R, Zhang PZ, Molnar P (2005) Bayesian inference of plastosphere viscosities near the Kunlun Fault, northern Tibet. Geophys Res Lett 32(1):L01302. doi:10.1029/ 2004GL021658

Hirn A, Lepine JC, Jobert G, Sapin M, Wittlinger G, Xu ZX, Gao EY, Wang XJ, Teng JW, Xiong SB, Pandey MR, Tater JM (1984) Crustal structure and variability of the Himalayan border of Tibet. Nature 307(5946):23-25

Hou H, Gao R, He R, Cai X, Liu J, Xiong X, Guan Y, Zeng L, Knapp JH, Roecker SW (2012) Shallow-deep tectonic relationship for the junction belt of western part of South Tianshan and Tarim basin-Revealed from preliminary processed deep seismic reflection profile. Chin J Geophys 55(12):4116-4125 (in Chinese with English abstract)

Huang GC, Roecker SW, Levin V (2011) Lower-crustal earthquakes in the West Kunlun range. Geophys Res Lett 38(1):L01314. doi:10.1029/2010GL045893

Hurukawa N (1983) $\mathrm{P}_{\mathrm{n}}$ velocity and moho-offset at the west of Lake Biwa in the Kinki district, Japan. J Phys Earth 31:33-46

Karplus MS, Zhao W, Klemperer SL, Wu Z, Mechie J, Shi D, Brown LD, Chen C (2011) Injection of Tibetan crust beneath the south Qaidam Basin: Evidence from INDEPTH IV wide-angle seismic data. J Geophys Res 116:B07301. doi:10.1029/2010JB007911

McGeary S (1989) Reflection seismic evidence for a Moho offset beneath the Walls Boundary strike-slip fault. J Geol Soc 146:261-269

Mechie J, Zhao W, Karplus MS, Wu Z, Meissner R, Shi D, Klemperer SL, Su H, Kind R, Xue G, Brown LD (2012) Crustal shear (S) velocity and Poisson's ratio structure along the INDEPTH IV profile in northeast Tibet as derived from wide-angle seismic data. Geophys J Int 191:369-384

Ryder I, Burgmann R, Pollitz. (2011) Lower crustal relaxation beneath the Tibetan Plateau and Qaidam Basin following the 2001 Kokoxili earthquake. Geophys J Int 187(2):613-630

Shi DN, Shen Y, Zhao WJ, Li AB (2009) Seismic evidence for a Moho offset and south-directed thrust at the easternmost Qaidam-Kunlun boundary in the Northeast Tibetan plateau. Earth Planet Sci Lett 288:329-334

Smart KJ, Ferrill DA, Morris AP, McGinnis RN (2012) Geomechanical modeling of stress and strain evolution during contractional fault-related folding. Tectonophysics 576-577:171-196

ten Brink US, Schoenberg N, Kovach RL, Ben-Avraham Z (1990) Uplift and a possible Moho offset across the Dead Sea transform. Tectonophysics 180:71-85

Vergne J, Wittlinger G, Hui Q, Tapponnier P, Poupinet G, Mei J, Herquel G, Paul A (2002) Seismic evidence for step-wise thickening of the crust across the NE Tibetan Plateau. Earth Planet Sci Lett 203:25-33

Wang CS, Gao R, Yin A, Wang HY, Zhang YX, Guo TL, Li QS, Li YL (2011) A mid-crustal strain-transfer model for continental deformation: A new perspective from high-resolution deep seismic-reflection profiling across NE Tibet. Earth Planet Sci Lett 306:279-288

Wang H, Gao R, Yin A, Xiong X, Kuang C, Li W, Huang W (2012) Deep structure geometry features of Haiyuan Fault and deformation of the crust revealed by deep seismic reflection profiling. Chin J Geophys 55(12):3902-3909 (in Chinese with English abstract)

Wang YX, Mooney WD, Yuan XC, Okaya N (2013) Crustal Structure of the Northeastern Tibetan Plateau from the Southern Tarim Basin to the Sichuan Basin, China. Tectonophysics 584:191-208

Wittlinger G, Vergne J, Tapponnier P, Farra V, Poupinet G, Jiang M, Su H, Herquel G, Paul A (2004) Teleseismic imaging of subducting lithosphere and Moho offsets beneath western Tibet. Earth Planet Sci Lett 221(1-4):117-130

Yamasaki T, Houseman GA (2012) The crustal viscosity gradient measured from post-seismic deformation: A case study of the 1997 Manyi (Tibet) earthquake. Earth Planet Sci Lett 351-352:105-114

Zhang ZJ, Wang YH, Chen Y, Houseman GA, Tian XB, Wang ER, Teng JW (2009) Crustal structure across Longmenshan fault belt from passive source seismic profiling. Geophys Res Lett 36:L17310. doi:10.1029/2009GL039580

Zhu LP, Helmberger LV (1998) Moho offset across the northern margin of the Tibetan Plateau. Science 281:1170-1172 